\title{
MAPUZUGUN Y LOS PROCESOS DE COLONIZACIÓN
}

\author{
Mapuzugun and colonization process
}

\author{
Elba Soto*
}

\section{RESUMEN}

Desde la perspectiva discursiva francesa y tomando como base mis investigaciones referentes al Pueblo Mapuche de Chile, el objetivo de este artículo es aportar con nuevas comprensiones respecto al mapuzugun o lengua mapuche, pensada como una lengua en relación, en Chile, un país que se constituye a partir de la colonización. Considerando que en la lengua y su realización, el discurso, se materializa el contacto entre lo ideológico y lo lingüístico, colocamos el foco en cómo los sujetos se significan y cómo el confronte entre la lengua mapuche y la lengua nacional moviliza sentidos y establece fronteras e identificaciones, para el sujeto pensado discursivamente. Desde ese lugar de sentidos, afirmamos que el futuro de los llamados 'pueblos indígenas' depende mayoritariamente de que las 'lenguas indígenas' puedan ser 'dichas'.

Palabras claves: Análisis de discurso francés, lengua mapuche, lengua nacional, colonización, significados.

\begin{abstract}
From the French discursive perspective and having as a base my research related to the Mapuche People from Chile, the objective of this article is to bring new understandings regarding the mapuzugun or mapuche language, thought as a language in relation, in Chile, a country constituted from colonization. Considering that in the language and its realization, the discourse, the contact between the ideological and the linguistic is materialized, we are focused in how subjects signify themselves and how the confrontation

* Investigadora del Núcleo Científico Tecnológico de Ciencias Sociales, Universidad de La Frontera. Temuco, Chile. Correo: weichapan@gmail.com.

Artículo recibido el 31 de julio de 2012. Aceptado para publicación el 18 de julio de 2013.
\end{abstract}


between the mapuche language and the national language moves meanings and establishes frontiers and identifications for the subject thought discursively. From that lotus of meanings, we can say that the future of the so called 'indigenous people' depends mostly on that the 'indigenous languages' can be 'said'.

Keywords: French Discourse Analysis, mapuche language, national language, colonization, meanings.

\section{CON-TEXTUALIZANDO NUESTRO OBJETO}

Tratar el tema de las lenguas de los Pueblos Originarios de América es urgente, si lo que interesa es contribuir a re-pensar lo que éstas significan, en un momento histórico en que esa reflexión y análisis pueden ser determinantes, ya que muchas de las lenguas indígenas de América que aún sobreviven, se encuentran en peligro de extinción; es decir, en franco riesgo de desaparición. Aunque la necesidad de salvar éstas lenguas de la extinción, debemos reconocer, es un asunto polémico. Ese cuadro sinóptico muestra la premura de visibilizar sentidos que nos permitan clarear esa discusión, pues para nuestras realidades, como asegura Orlandi (1990: 13), lo que es visto, adquiere el estatuto de existencia.

En esa perspectiva, en este artículo me aboco a la reflexión de la lengua mapuche o mapuzugun como proceso discursivo, desde la óptica del Análisis de Discurso francés y en base a los resultados de la investigación académica sobre el Pueblo Mapuche que realizo hace más de quince años. El objetivo que orienta este artículo es mostrar la trascendencia de la lengua en la permanencia de las culturas e identidades indígenas.

$\mathrm{Al}$ respecto, es necesario acotar que en la óptica discursiva nuestro presente y la historia no significan como hechos cronológicos cuyos sentidos estarían 'dados' o serían 'evidentes'. Según Henry (1997: 51-52), no hay hecho o evento histórico que no pida interpretación, que no reclame sentidos. En esa perspectiva, lo que aquí interesa, discursivamente, es comprender cómo las lenguas en relación (mapuzuguncastellano) significan como procesos socio-históricos, cuáles son sus sentidos, cómo eso marca la forma en que se establece o no la interlocución entre distintos y la forma en que esos sujetos distintos se significan y significan el entorno social.

Pues como afirma Lagazzi (2003: 85), en esta perspectiva discursiva nos distanciamos de enfoques que toman los sentidos como contenidos intrínsecos a las palabras ya que, como indica la misma autora, en nuestra condición de personas 
-contradictoriamente- es por nuestra ansiedad de organizar y estabilizar el mundo que imaginariamente 'pegamos' (significando adherir) los sentidos a las palabras, 'pegamos' las palabras a las cosas y somos movilizados permanentemente en un juego de imágenes. Imágenes de quién somos y quiénes son los otros, imágenes de lo que pensamos y de lo que piensan los otros, etc. Imágenes que se fijan como siendo la realidad, haciéndonos olvidar que las realidades son muchas y que lo que las determina son condiciones que escapan a nuestro control y estabilizan itinerarios de sentidos, constituyendo así lo que denominamos historia.

El Análisis de Discurso nos ofrece esos nuevos lugares de comprensión y desde su especificidad nos permite interpretar la lengua entendida como proceso discursivo, considerando, entre otras cosas, sus condiciones de producción. Dicho de otra forma, buscando articular la lengua con su exterioridad, es decir, con el sujeto y la situación (Soto, 2012: 12-13). No obstante, hablar de lenguas nos exige situarnos, indicar el lugar desde el cual haremos la reflexión que contribuirá a la producción de conocimiento relativo al tema que nos interesa. Por tanto, es relevante aclarar dos cosas: en el Análisis de Discurso francés no se trabaja con la lingüística inmanente, sino con la lingüística en relación al campo social y el Psicoanálisis y no interesa la lengua como objeto de estudio, sino el discurso, es decir, la lengua en relación, la lengua en movimiento, la lengua en la historia. El discurso como puente entre la lengua y la ideología.

Si pensamos que el sujeto se constituye como tal en el lenguaje y que es ahí donde el sujeto del discurso deja las marcas de ese proceso ideológico, es en el lenguaje donde podemos encontrar las pistas para llegar más cerca del sujeto y de la forma en que él se significa. Con ese enfoque, el Análisis de Discurso presupone una metodología lingüística, sin nunca dejar de considerar lo histórico, lo ideológico y el inconsciente, como inscritos en el discurso. Como observa Orlandi (2012: 21) "en el Análisis de Discurso se busca comprender la lengua teniendo sentido, como trabajo simbólico, parte del trabajo social general, que es constitutivo del hombre y de su historia”, entendiendo que la lengua y la historia afectan al sujeto discursivo ${ }^{1}$ y que éste no tiene control sobre la forma en que la lengua y la historia lo afectan.

\footnotetext{
${ }^{1}$ Es importante destacar que para el Análisis de Discurso francés 'sujeto discursivo' no es lo mismo que 'sujeto jurídico’. El sujeto discursivo está relacionado a la forma-sujeto, al sujeto ideológico. Es el sujeto que (se) significa determinado por las condiciones históricas. Por otro lado, el sujeto jurídico es una forma-sujeto específica. Es el sujeto individualizado por el estado, sujeto a deberes y derechos. Como expone Orlandi (2012: 52), la evidencia del sujeto, o mejor dicho su identidad, borra el hecho de que ella resulta de una identificación, que se da ideológicamente por una inscripción en una formación discursiva, que en una sociedad como la nuestra, lo produce bajo la forma de sujeto de derecho (jurídico). Forma-sujeto que corresponde, históricamente, al sujeto del capitalismo, determinado por condiciones externas y al mismo tiempo autónomo, sujeto a deberes y derechos.
} 
Se trata de un sujeto de lenguaje que funciona atravesado por el inconsciente y la ideología. Dicho de otra forma, aunque pueda parecer tautológico, discursivamente se discute la idea de un sujeto centrado, se cuestiona lo que llamamos la ilusión subjetiva que nos coloca como origen del lenguaje, ilusión dada -como explica Orlandi (1999: 18) - "por el efecto ideológico elemental, por el cual, el sujeto, siendo siempre ya-sujeto se coloca en el origen de lo que dice". Un sujeto que se constituye interpelado por la ideología, donde ideología e inconsciente, articulados, funcionan disimulando su propia existencia.

Debemos agregar que en el Análisis de Discurso francés no se valida la noción psicológica de sujeto empíricamente coincidente consigo mismo. Lo que hay son posiciones de sujeto ${ }^{2}$. El sujeto es estructuralmente dividido desde su constitución y solo tiene acceso a parte de lo que dice. La falla lo constituye, del mismo modo que constituye a la lengua. Espacio de interpretación ${ }^{3}$, instancia de ideología, el sujeto es pensado discursivamente como posición, entre otras, donde el sujeto no tiene acceso efectivamente a la exterioridad que lo constituye; estando siempre-ya preso a redes de filiaciones de sentidos (Orlandi, 1998a: 18-19).

Es productivo relevar que en este enfoque discursivo se trabaja con un concepto de ideología relacionado al lenguaje, distinto de aquel que habitualmente se utiliza en las Ciencias Sociales. Un concepto que considera el lenguaje como no transparente, que discute la evidencia de los sentidos. Lo anterior significa, entre otras cosas, "que las palabras, las expresiones, proposiciones, etc. reciben sus sentidos de la formación discursiva (formación ideológica) en la cual son producidas", siendo la lengua la base común de procesos discursivos diferenciados (Pêcheux y Gadet, 1998: 15). En otras palabras, discursivamente, la ideología no es ocultación de la realidad sino - propiamente- condición necesaria para la constitución del sujeto y los sentidos, función de la relación necesaria entre el lenguaje y el mundo para que se signifique; donde el efecto de sentido del discurso aparece como una relación determinada del sujeto -afectado por la lengua- y la historia (Orlandi 2012: 53-54).

\footnotetext{
2 "El sujeto significante, el sujeto histórico (material), ese sujeto que se define como posición-sujeto, es un sujeto que se produce entre diferentes discursos, en una relación regulada por la memoria del decir (el interdiscurso), definiéndose en función de una formación discursiva en relación con las demás" (Orlandi, 1996: 49). No es una forma de subjetividad sino un "lugar" que ocupa para ser sujeto de lo que dice. Es la posición que debe y puede ocupar todo individuo para ser sujeto de lo que dice (Orlandi, 2012: 55-56).

3 "Ante cualquier hecho, ante cualquier objeto simbólico, somos instados a interpretar. Habiendo una inyunción a interpretar". (Orlandi, 2012: 18). En todo momento estamos interpretando la realidad, en/con la ilusión de que esa fuese la única interpretación posible. Interpretación que, como indica Lagazzi (2007: 11), está determinada por sus condiciones de producción. Es decir, los sentidos tienen historia.
} 
Reflexionando sobre la relación entre discurso e ideología, Pêcheux y Fuchs (1997: 166) afirman que "es imposible identificar ideología y discurso (lo que sería una concepción idealista de la ideología como esfera de las ideas y de los discursos) sino que se debe concebir el discurso como uno de los aspectos materiales de lo que llamamos materialidad ideológica”.

Con relación al discurso, este es el lugar de acceso y observación de la relación entre la materialidad específica de la ideología y la materialidad de la lengua, en la relación lengua-discurso-ideología. Es decir, queda claro que la ideología aquí es re-significada, dejando de ser concebida como lo era en la Filosofía y en las Ciencias Sociales para adquirir un nuevo sentido: el que se establece cuando pensamos la propia producción de los sujetos y de los sentidos. Así, se invierte el polo de observación: no se parte de los sentidos producidos, sino que se observa el modo de producción de sentidos y de la constitución de los sujetos; y ahí no se puede prescindir, por un lado, del lenguaje y por otro, de la ideología (Orlandi, 2003: 12). En otras palabras, el discurso es el lugar en que observando esa relación entre lengua e ideología, comprendemos como la lengua produce sentidos por los sujetos y para los sujetos y como esa constitución de los sujetos y de los sentidos es históricamente determinada.

Una determinación histórica afectada por lo que llamamos relaciones de fuerza. O sea, el lugar a partir del cual el sujeto habla, es constitutivo de lo que él dice. En una sociedad como la nuestra, argumenta Orlandi (2012: 46), constituida por relaciones jerarquizadas, son relaciones de fuerza, sustentadas en el poder de esos diferentes lugares las que se validan en la 'comunicación'. En palabras de Foucault (1996: 10): "el discurso no es simplemente aquello que traduce las luchas o los sistemas de dominación, sino aquello por lo que se lucha, el poder del cual nos queremos apoderar" y según Maingueneau (1998: 43): "tomado en su acepción más amplia, aquella que tiene en Análisis de Discurso, ese término designa menos un campo de investigación delimitado que un cierto modo de aprehensión del lenguaje, este último no considerado aquí como una estructura arbitraria sino como una actividad de sujetos inscritos en contextos determinados". Como vemos, el discurso en esta perspectiva es tomado como un concepto que no se confunde ni con el discurso empírico sustentado por los sujetos ni tampoco refiere a textos (pensados como objeto lingüístico) ya que, como señala Maldidier (2003: 21) 'revienta' cualquier concepción comunicativa del lenguaje. 
Hablamos con palabras queya tienen sentido, podemos decir que heredamos las palabras y sus significados. De esa forma, en el discurso no hay sentidos literales guardados en algún lugar y que aprendemos a usar. En los procesos de sentidos o significados de los discursos hay transferencias de sentido, juegos simbólicos de los que no tenemos control y en los cuales el equívoco, la ideología y el inconsciente están presentes (Orlandi: 2012: 38-41).

En esa perspectiva, también la memoria discursiva (interdiscurso) forma parte de la producción del discurso. Es decir, el saber discursivo posibilita todo decir y retorna bajo la forma de lo pre-construido ${ }^{4}$, lo ya-dicho que está en la base de lo decible, sustentando lo que se dice cada vez que se toma la palabra. Memoria que 'acciona' colocando en funcionamiento las condiciones de producción del discurso, relativas a los sujetos y la situación (Orlandi, 2012: 37-38). Según la misma autora (1999a: 15) lo que tiene sentido en la memoria es que ella significa y por tanto, pasa a integrar el mundo de la cultura; proceso que no es consciente, o sea, no depende de aprendizajes sino que se da por filiación de sentidos. Y agrega: "mucho de la cultura no es aprendido, se sabe por filiación".

Lo que nos permite decir que el discurso se inscribe en la historia y 'hace historia'. El discurso es historia y está en la historia. En palabras de Orlandi (1988a: 10), el discurso (un texto o un decir) no es una sumatoria de palabras, tampoco es una sumatoria de frases o de interlocutores y menos aun se agota en un espacio cerrado. Tiene relación con la exterioridad, con sus condiciones de producción.

Desde ese lugar de significación, en este artículo interesa mostrar cómo el confronte entre la lengua mapuche y la lengua nacional moviliza sentidos y establece fronteras e identificaciones por y para los sujetos. Cuestiones de poder y no-poder, que visibilizadas discursivamente pueden contribuir, entre otras cosas, a re-pensar las políticas lingüísticas históricamente presentes en Chile y América Latina. Un tema que entendemos es impostergable, si pensamos que el mundo se encuentra enfrentado a procesos globalizantes que orientan la sociedad planetaria hacia una 'lógica uniformadora' que conduce nuestro planeta hacia la homogenización cultural versus múltiples movimientos alternativos que propugnan variados proyectos sociales, que aun siendo disímiles se tocan cuando se trata de reivindicar horizontes que conduzcan hacia la 'unidad en la diversidad', objetivando así la alteridad, contrariando e intentando superar la lógica dominadora del modelo capitalista progresista.

4 Pre-construido: "corresponde a lo siempre-ya-ahí de la interpelación ideológica que entrega-impone la "realidad" y su "sentido" bajo la forma de universalidad (el mundo de las cosas)" (Pêcheux 1995: 164). Es decir, son aquellos sentidos ya puestos como siendo lo real, la exterioridad que determina al sujeto discursivo (sujeto ideológico). 
Con ese enfoque, el de buscar espacios de comprensión que permitan la convivencia armónica en el planeta, nos proponemos mostrar nuevas comprensiones que viabilicen el diálogo o, dicho de otro modo, la inter-locución entre el Pueblo Mapuche, el estado nacional y la sociedad chilena. Nuestro empeño específico en este artículo es mostrar la lengua mapuche como proceso socio-histórico y su relación con la memoria constitutiva de una cultura diferente. Es decir, su relación inmanente con lo que llamamos la cultura, ideología y visión de mundo de un pueblo. Nos interesa mostrar que el futuro de los pueblos llamados indígenas depende mayoritariamente de que sus lenguas puedan 'ser dichas'.

\section{LA LENGUA COMO PROCESO DISCURSIVO}

En el inicio de este nuevo milenio, hablar de lenguas en relación y de la lógica de hegemonías que atraviesa las relaciones sociales entre pueblos y/o naciones que ocupan el mismo territorio, es una cuestión de poder y discurso. Respecto a las condiciones de producción o contexto socio-histórico de las lenguas que nos convocan en este artículo, podemos decir que, de un lado, se trata de los mapuche de Chile históricamente significados como una nación indígena y del otro lado, se trata de una república que se constituyó a partir de la colonización, lugares de significación que se mantienen hasta los días de hoy en la forma en que se establecen las relaciones entre esas distintas identidades presentes en el país. De ese modo, pensar en el mapuzugun es pensar esta lengua indígena en relación a la lengua nacional, en este caso el castellano, es pensar en la cuestión del poder, del poder decir, del poder - que se tiene o no se tiene- para decir(se).

Concordamos con Orlandi (1988b: 8) cuando afirma que reflexionar sobre las lenguas indígenas en América es comenzar por la raíz, pues esa es una cuestión omnipresente y subyacente a varias otras cuestiones que forman parte de la relación entre lenguas o formas de lenguaje en el continente americano. La misma autora (1990: 27) explica que el Análisis de Discurso se constituye justamente en la región que se refiere a la relación del lenguaje (objeto lingüístico) con su exterioridad (objeto histórico). Siendo así, el contexto social e histórico de los procesos discursivos aquí focalizados -el castellano y el mapuzugun-, pensados como procesos socio-históricos de lenguas en relación, se torna significativo. De ese modo, a continuación hago una breve síntesis de aspectos a considerar discursivamente, si pensamos en la trayectoria de una de las lenguas llamadas 'lenguas indígenas', en Chile. Como muestro en diversas investigaciones (Soto 
2006: 6-7; 2007: 86-87; 2011a: 168-169), respecto a la acción del estado podríamos hablar de más de un siglo de apagamiento e interdicción de las lenguas y memorias de las denominadas 'minorías étnicas' en Chile. Respecto a la sociedad chilena, de manera general, podríamos hablar de procesos que han estabilizado los sentidos del discurso de la colonización (el discurso de la cultura hegemónica) y su lengua, sobre las llamadas 'culturas y lenguas indígenas', silenciando, apagando e interdictando lenguas y memorias indígenas. En otras palabras, desde la sociedad chilena y el estado se ha impuesto y aun se impone la forma de significarse chileno, que 'instala a manera de estanque' los sentidos de unidad nacional (un pueblo, una cultura, una lengua) en las formaciones imaginarias de la sociedad chilena y concomitantemente mantiene vigente las relaciones de fuerza y los sentidos de sometimiento y dominación del discurso de la colonización, al tiempo que prohíbe, silencia y niega lo que parece distinto frente a ese 'paisaje socio-cultural', como son las memorias y lenguas indígenas.

Lo expuesto anteriormente sintetiza el proceso discursivo de apagamiento, silenciamiento e interdicción del mapuzugun desde la incorporación de la nación Mapuche a la República de Chile 5 . Pues se trata de la trayectoria de una lengua inserta en lo que se ha llamado 'relaciones inter-étnicas' de desigualdad (Soto, 2006: 9-14), lo que, consecuentemente, ha llevado la lengua mapuche o mapuzugun a una condición de extrema fragilidad, lo cual el propio estado chileno en estos días refiere como 'lengua en peligro de extinción'.

Por otro lado, en Chile discursivamente se vehicula solamente una versión de la historia, la oficial y los medios de comunicación visibilizan una versión de los hechos que marcan el presente del mundo 'indígena', la versión discursiva hegemónica: empresarial y del estado (Soto 2011b: 101-102). Se vehicula la versión de la historia y del presente construida por la sociedad hegemónica, que, como ya señalamos, estabilizó y estabiliza los sentidos de unidad e igualdad nacional. Es decir, los sentidos de una nación y un pueblo homogéneo, donde el castellano sería la única lengua vigente en el país. Espacio discursivo en el cual los pueblos y/o naciones indígenas presentes en el país han sido negados como

5 Cabe recordar que esa negación está presente desde las primeras leyes de educación. La Ley de Instrucción Primaria del 24 de noviembre de 1860 (antes de la incorporación oficial de los mapuche al país, en 1881), que se ha catalogado como "uniformadora", establece que en Chile, los establecimientos escolares entregarán un tipo de saber y enseñarán una lengua, la nacional (Soto, 2006: 9). La ley que la sustituye, conocida como Ley 3.654, de Instrucción Primaria Obligatoria del 26 de agosto de 1920 (época en que los mapuche jurídicamente ya eran ciudadanos nacionales), establece que en las escuelas se enseñará el idioma patrio; silenciando las otras lenguas presentes en el país (Soto, 2006: 45-50). Es decir, el proceso de escolarización funcionando como proceso de estabilización del castellano, para lo cual se apagan otras lenguas también presentes, vistas como elementos que provocarían inestabilidades en la instalación del castellano como idioma hegemónico y el único a ser hablado en Chile (Soto, 2006: 50). 
alteridad o simplemente negados como la posibilidad de ser otros (Soto, 2004: 104). Negación que se ha materializado en el 'desmantelamiento' de las lenguas, el apagamiento del sujeto indígena y la interdicción de su memoria; en fin, todo lo que comprende lo relativo a las 'culturas indígenas' en el país (Soto, 2004': 109111; 136-138; 2006: 77-78).

Desde esos lugares de significación y tomando la complejidad conceptual que nos ofrece el Análisis de Discurso, nos aproximamos al tema que nos interesa mostrando algunos términos - usados en Chile, en los espacios discursivos mapuche y no-mapuche- y la forma en que éstos son significados:

- Winka: esta palabra mapuche hoy -mayoritariamente- se significa como extranjero, chileno; persona no-mapuche; siendo que en su origen estuvo asociada a la palabra winküfe, que significaría asaltante o ladrón.

- Logko: esta palabra del mapuzugun (etimológicamente significa cabeza) originalmente, al ser utilizada por los mapuche en el plano social habría sido significada -entre otras cosas- como persona que guia a su comunidad. Sin embargo, hoy también se significa como jefe o su paráfrasis, persona 'superior'. Es decir, conlleva el sentido de jerarquía, de grado u otro semejante -sentidos que no existían entre los mapuche en el momento en que entran en contacto con los no-mapuche que llegan a su territorio-, ya que los efectos de sentido de la palabra jefe, denotan un estilo de relaciones sociales verticalista, que -según nuestros estudios de esa cultura- no era propio de la sociedad mapuche, donde los roles sociales tenían sentidos de funcionalidad, lo que no los significaba como jerarquía. En síntesis, la palabra logko como es utilizada por los mapuche en la actualidad ha dado lugar a que otros sentidos entren en el espacio de lo posible y se historicicen ${ }^{7}$.

- Igualdad: esta palabra del castellano, en el discurso hegemónico -discurso estabilizado, discurso que permanece- tiene el efecto de sentido de que todas las personas son iguales y por tanto tienen los mismos derechos y deberes. En esa perspectiva -donde se considera que todos son iguales y tienen las mismas oportunidades-, como indica Pfeiffer (2001), si una persona no consigue 'progresar', se considera que es porque no se esfuerza

\footnotetext{
${ }^{6}$ Mi tesis de doctorado, defendida en la Universidade Estadual de Campinas / UNICAMP, Brasil, el año 2004 y publicada en Brasil el ańo 2007 por el Centro de Memoria de la UNICAMP y la Editora Arte Escrita, con apoyo financiero de la Fundación de Apoyo a la Pesquisa (Investigación) Académica del Estado de São Paulo / FAPESP. En la bibliografía de este artículo está referida con el año de publicación.

${ }^{7}$ Historicizar es un término técnico de esta línea discursiva. Significado como 'hacer historia' (Soto en Orlandi, 2012: 38).
} 
lo suficiente, pues tiene las mismas oportunidades que el resto de las personas. Consecuentemente, como muestra la misma autora, la forma en que ese concepto es significado estaría enmascarando las desigualdades. Por otro lado, desde espacios de interpretación críticos al modelo capitalista progresista, este concepto, entre otras cosas, se asocia al sentido de negación de un otro, de un distinto, no habiendo lugar para el diferente.

- Minoría: esta palabra del castellano, según el discurso dominante relacionado a lo que se entiende como 'sentido común'- se refiere a las personas que están en desmedro de los demás, por alguna circunstancia, por lo que necesitan ser ayudados. Entonces, serían 'unos pocos' que no consiguen sustentarse, 'valerse por sí mismos'. Mas, desde una interpretación crítica frente al paradigma hegemónico, ese término tendría, entre otros, el efecto de sentido de negar las 'minorías', que, contradictoriamente a la forma en que son significadas desde el modelo capitalista, representan a la gran mayoría de los habitantes que pueblan este planeta y que se encuentran en espacios de 'desventaja', de negación, de desmedro, de privación, de marginación, de miseria; como las denominadas 'minorías étnicas'.

Como vemos, el sujeto y el significar no son transparentes y el funcionamiento del lenguaje no se explica solo por los factores internos al sistema lingüístico. Las palabras y los discursos establecen una historia, producen sentidos y también cambian de sentido en y por la historia, lo que nos permite entrever la complejidad inmanente a la constitución de los sentidos. Un mismo discurso o una misma palabra significa diferentemente, inclusive, como pudimos ver en los ejemplos anteriores, las palabras cambian de sentido según la formación ideológica (formación discursiva) de quien la dice o la escucha y esa constitución de sentidos está determinada socio-históricamente y es afectada por el inconsciente, algo sobre lo que no tenemos control.

Es productivo para el tema que nos convoca relevar la forma en que la palabra tierra es significada desde posiciones sujeto contradictorias, como son las posiciones del sujeto mapuche y el sujeto chileno empresario. Podemos decir que desde la posición-sujeto mapuche, la palabra tierra (mapu en lengua mapuche) tiene un valor simbólico, espiritual; mientras que en la lógica del empresario occidental, es decir, en la posición-sujeto empresario (referido como winka, desde 
la posición-sujeto mapuche), la palabra tierra es significada como un bien de uso. Es decir, la posición del sujeto marca su discurso y debido a esto, incluso, cuando desde posiciones discursivas diversas intentamos decir 'lo mismo', lo hacemos de formas diferentes y significamos diferentemente. Pensemos en una formulación discursiva relativa a la (no) interlocución entre los mapuche y los winka, referida específicamente a la dificultad que existe para que se produzca el diálogo entre los mapuche y los empresarios agrícolas chilenos. Una formulación posible para los no-mapuche sería: "con los mapuche no nos entendemos" o una paráfrasis posible -en la misma región de sentidos- como la siguiente, "con esos indios no nos entendemos"; mientras que una formulación posible para los mapuche sería: "los mapuche y los winka no nos entendemos", o una paráfrasis como, "con los chilenos no nos entendemos"; lo que en nuestras investigaciones, analizando los discursos de los mapuche y de los no-mapuche en Chile, nos ha mostrado dos posiciones sujeto distintas, donde esos sujetos discursivos (mapuche y no-mapuche) entre ellos se significan como un otro. Sujetos distintos que se identifican con otras regiones de sentidos, otras formaciones ideológicas, entre las cuales no hay interlocución, sino que al contrario, hay enfrentamiento, hay inter-in-comprensión. Dos posiciones sujeto distintas: la del chileno y la del mapuche, señalando una frontera (Soto 2004: 134; 2006: 8; 2011a: 191).

A lo anterior, se suman otras cuestiones fundamentales que también determinan al sujeto y su forma de significar o no-significar. Según Orlandi (1999b: 65), hay "perforaciones", "vacíos" en la memoria, que son lugares, no en que el sentido se "oculta" sino, al contrario, en que el sentido "falta" por interdicción. Desaparece. Y eso ocurre porque toda una región de sentidos, una formulación discursiva, es apagada, silenciada, interdictada. No hay un olvido producido por ellos, sino sobre ellos. El sujeto discursivo "se queda sin memoria" relacionada a esa región de sentidos y esto impide que ciertos sentidos hoy puedan hacer (otros) sentidos. Como la memoria es, ella misma, condición de lo decible, esos sentidos no pueden ser leídos. De esa forma, los sentidos -excluidos, silenciados- no pueden significar, lo que redunda en que hay toda un área de la historia que (ya) no corresponde a un decir posible. A lo que podemos agregar que en apariencia se "instalan" otros sentidos, "sustituyendo" las antiguas significaciones. Tanto es así que en determinadas condiciones socio-históricas, hay sentidos que -debido a la censura, por el hecho de no poder ser formulados discursivamente y/o por el apagamiento de las memorias asociadas a esas regiones de sentidos- no pueden 
tener sentido por y para los sujetos y por tanto para las sociedades que estos conforman.

Como planteamos anteriormente, otra cuestión que determina la forma en que el discurso significa, que afecta la memoria, los silencios, el poder-decir o no-poder-decir, son sus condiciones de producción, específicas e identificables. En el caso del mapuzugun debemos considerar las relaciones de fuerza, es decir, la relación desigual que esta lengua experimenta frente a la lengua nacional -desde la incorporación de los mapuche a la República de Chile-, como sus condiciones de producción. Sobre ese asunto, es productivo incluir parte del discurso de un señor mapuche del Lago Lleu-Lleu, que el año 2002 nos habló de la forma en que él perdió su lengua materna, el mapuzugun, una historia bastante recurrente cuando se habla de ese asunto en las comunidades mapuche. Él nos dijo:

"El profesor [...] nos quitó la lengua, que nosotros hablábamos como nos enseñaba el padre. ¡La lengua mapuche! ;La prohibió! [...] después no pudimos hablar más, porque prohibió ipuh! Llegaban, nos guasqueaban y nosotros ipub! después, obligados a aprender, aprender, aprender en castellano"s.

En la perspectiva discursiva, la memoria constituye al sujeto y le posibilita el decir, no obstante, la memoria está expuesta a fallas, olvido, faltas, prohibición, censura. En el caso del trecho discursivo expuesto, las evidencias visibilizan que se trata de un proceso de prohibición, interdicción, negación, silenciamiento de la lengua mapuche. Si observamos con detalle la forma de ese discurso, podemos ver que él comienza diciendo, "nos quitó la lengua" y para eso usa el verbo quitar, que lingüísticamente significa tomar algo apartándolo del sitio en que estaba o, tomar, coger algo ajeno, hurtar, robar. Lo que pasa el efecto de sentido de que ese sujeto discursivo está acusando a su profesor de haberlo separado de su lengua, de habérsela robado; lo que está lejos de la indiferencia con que se trata el tema de la pérdida de las lenguas indígenas en la sociedad chilena y la institucionalidad que la constituye. Pues ahí hay efectos de sentido de dolor y rabia por la pérdida de su lengua, lo que según la forma en que está significando ese discurso ha ocurrido contra la voluntad de las personas mapuche, en este caso, de los niños en las escuelas. Luego él dice: "nos guasqueaban". O sea, les daban latigazos, los golpeaban y al decirlo habla en plural, lo que significa que no era solo él quien sufría esas torturas, sino que también otros niños las sufrían. Lo que visibiliza

\footnotetext{
${ }^{8}$ Ese trecho discursivo forma parte de nuestra tesis de doctorado, publicada en Brasil, con el nombre: "Sonhos e lutas dos mapuche do Chile".
} 
los efectos de sentido de una pérdida sufrida con violencia. Y termina diciendo: "después, obligados a aprender, aprender, aprender en castellano", lo que muestra que para ese señor, aprender el castellano fue algo impuesto (él fue "forzado"), él fue obligado a aprender el castellano a través de la violencia. Por último, si nos fijamos en la reiteración del verbo aprender (lo dice tres veces), cuando se refiere al aprendizaje del castellano, podemos percibir que ahí hay sentidos de hastío, de dolor y rabia, al recordar la pérdida de su lengua y el sometimiento que significó hablar en/el castellano. Me parece productivo agregar un trecho más de ese proceso discursivo, con palabras del mismo señor del Lago Lleu-Lleu que, al reclamar su lugar como sujeto discursivo, nos muestra otros sentidos del proceso de silenciamiento de su lengua. Veamos:

"[...] ahi me acuerdo yo del colegio, cuando el profesor nos dijo: ;no queremos lengua mapuche! Entonces ahi es donde me molesta a mí. Digo [...] inos cortaron y, en lo más nuestro, nos cortaron! Entonces, ahi donde debiamos haber aprendido nosotros para saber hablar correctamente, igual como se sabe el castellano. Pero, ¡no nos dejaron! Entonces, ahi es donde me siento molesto yo ipub! [...].

Si nos remitimos a la primera parte de ese discurso, las evidencias de ese trecho nos muestran una reiteración de sentidos, relacionados al dolor por la pérdida de la lengua materna. Sin embargo, ahí hay algo más. Buscando otros sentidos nos preguntamos, cómo es significada esa pérdida, cuando el sujeto discursivo dice: “¡nos cortaron y, en lo más nuestro, nos cortaron!”. Reparamos en el verbo cortar y su significado, dividir algo o separar sus partes, lo que visibiliza el efecto de sentido de que al prohibir el mapuzugun no tan solo se estaría negando el derecho a hablar esa lengua sino que se estaría "separando al sujeto mapuche de su lengua”, lo que queda más claro si nos fijamos en el pronombre posesivo nuestro, cuando el sujeto dice: en lo más nuestro, nos cortaron, ya que ahí queda de manifiesto que la pérdida es significada como la separación de algo que el sujeto considera suyo. En otras palabras, una pérdida que él considera grave para su ser mapuche. Si pensamos que es en la lengua que nos constituimos como sujetos, esos sentidos se tornan incuestionables.

Por último, nos enfocamos hacia el momento en que se dice: "entonces, ahí donde debíamos haber aprendido nosotros para saber hablar correctamente, igual como se sabe el castellano. Pero, ¡no nos dejaron!”, observamos una nueva evidencia, donde se contrapone el deseo (frustrado) del sujeto de que se le hubiese enseńado su lengua en la escuela, para hablarla correctamente, versus el hecho 
histórico de que no los dejaran, de que ese derecho se les haya negado (a él y a otros niños mapuche). Si nos detenemos en el pronombre personal nosotros, cuando él dice, donde debíamos haber aprendido nosotros, percibimos que en ese dicho, nosotros, hay un ellos, no-dicho, pero que igualmente significa, en este caso una contraposición, una relación de fuerzas desigual, donde el efecto de sentidos es un "nosotros", "sometidos por ellos", donde el pronombre ellos nos remite a la sociedad chilena y el estado, en su identificación con la formación discursiva de unidad nacional.

En síntesis, podemos decir que los mapuche, al haber sido y ser sometidos a la lengua nacional, el castellano, prácticamente en todos los espacios de su vida, significan ese hecho discursivo como una imposición, como la interdicción de algo que les era propio y de lo cual fueron y son separados violentamente, su lengua; lo que también significa borrar de su memoria, sacar de su memoria su forma de interpretar el mundo e identificarse como sujetos socio-históricos.

Payer, en base a sus investigaciones sobre la presencia de otras lenguas, distintas a la lengua nacional, en Brasil, concluye que el discurso de unidad nacional de la lengua (lo que también se válida para otros países latinoamericanos) ha actuado como práctica de nacionalización, interdictando jurídicamente esas otras lenguas. Un discurso producido a partir de la perspectiva del estado, que puede ser entendido como una "política del silencio". Una política que -al prohibirlasno solo niega el derecho a que otras lenguas puedan ser dichas sino que también apaga las memorias discursivas que las sustentan (Payer, 2001: 237-238). En otras palabras, ese no-poder-decir, esa interdicción del decir, esa censura, que prohíbe que el sujeto indígena se constituya como sujeto indígena en su lengua, actúa como silenciamiento de la memoria constitutiva del sujeto, entendida en su historicidad.

Orlandi (1989: 43) explica que en la perspectiva discursiva francesa, con relación a la "política del silencio", estamos hablando de no-dichos que deben permanecer no-dichos, que representan un apagamiento de sentido, que representan los no-dichos que descartan los sentidos no deseados, aquellos que es necesario evitar: el no-dicho necesariamente excluido. No obstante, la relación entre el silenciamiento de la lengua y la constitución del sujeto se da de maneras diversas y particulares, según las formas a través de las cuales funciona el apagamiento en la historia (Payer, 1999: 161).

9 Según Orlandi (1995: 75), la política del silencio se define por el hecho de que al decir algo apagamos necesariamente otros sentidos posibles, pero indeseables en una situación discursiva dada. 
$\mathrm{Al}$ respecto, es interesante observar lo que afirma Rodrigues de Alcalá (2001: 26), describiendo la relación entre los 'pueblos indígenas' y las sociedades latinoamericanas, cuando declara que la 'civilización' en América Latina, a partir de modelos urbanos europeos, coincide con el apagamiento de las culturas locales, las culturas indígenas, consideradas no civilizadas, no evolucionadas o inferiores, donde civilizado es al mismo tiempo evolucionado, significando superior y urbano, estando las culturas indígenas excluidas de los dos sentidos del término. Polisemia del término civilización -tal como es movilizado en los discursos de la (sobre la) colonización- que produce una confluencia característica en la comprensión de esa realidad cultural, dejando a las culturas y lenguas indígenas excluidas de la civilización, por ser consideradas no civilizadas (es decir, primitivas e inferiores). Lo que nos indica que -en la exclusión de las 'lenguas indígenas' por los estados y las sociedades americanas- se ha mantenido la perspectiva del colonizador, que continúa buscando 'imponer la civilización propia y superar la barbarie de los no civilizados', significando, de ese modo, los procesos de silenciamiento e interdicción de las 'culturas indígenas' y sus lenguas como procesos de sustitución de esas culturas y lenguas por las nacionales, en pro del desarrollo de los indígenas y no como parte del silenciamiento y negación de esos pueblos.

En este punto, es fundamental recordar que en el caso de Chile estamos hablando de un país de colonización, en que la República ha orientado grandes esfuerzos a imponer el sentido de unidad nacional, para lo cual los gobiernos, históricamente, han desarrollado ingentes esfuerzos buscando apagar las diferencias presentes en el país, como son, específicamente, las que presentan los pueblos denominados indígenas, sus culturas y sus lenguas (Soto, 2006: 48).

Lo anteriormente expuesto visibiliza que las lenguas tienen una trayectoria histórica de relaciones de fuerza. Entonces - considerando esas relaciones sociohistóricas de poder-, debemos reconocer que el solo hecho de hablar, de poderdecir, de poder-decirse en una lengua determinada es una práctica política. Así, hablar de lenguas implica, necesariamente, hablar de políticas de lenguaje o políticas lingüísticas y también de políticas educativas o de escolarización. Pues hablar de lenguas y sus relaciones es discutir formas de lo político, siendo lo político constitutivo del lenguaje. En esa lógica, no podemos dejar de relevar, dada su importancia, que la política lingüística y de escolarización del estado chileno, desde su origen (hasta hace poco) ha sido de interdicción, de negación de las lenguas y las culturas indígenas, todo eso justificado como una política 
necesaria para la unidad nacional. Sabemos que en la actualidad hay cambios en el discurso del estado, en el sentido de favorecer a 'las minorías étnicas' y las 'lenguas indígenas', sin embargo esto aún no se concreta de manera efectiva en políticas públicas que permitan re-definir el estilo de relaciones entre los 'indígenas' y los 'no-indígenas' que con-forman la República de Chile.

Es decir, en el discurso dominante en el Chile de hoy aún se impone la lógica de la igualdad y la voz de las llamadas 'minorías étnicas' es silenciada. Los sentidos del discurso hegemónico son estabilizados y la forma de significar y de significar-se del sujeto indígena es afectada por pre-construidos (aquí relacionados con prejuicios y estereotipos) vehiculados por el discurso dominante. A manera de ejemplo, estereotipos como 'indio ignorante', 'indio borracho', 'indio incapaz', 'indio flojo', dominan los espacios de significación en Chile, y el propio apelativo 'indio' arrastra la carga de sentidos de ignorancia, alcoholismo, incapacidad y flojera, por lo cual en el país el solo hecho de ser llamado 'indio' es considerado un insulto. Por otro lado, en la sociedad chilena no se abren espacios que permitan resignificar a los 'indígenas', no se abren espacios para el discurso del sujeto indígena y su forma de significar y significar-se, que lo estimulen a valorar su origen, su cultura y su lengua. En síntesis, no se escucha al mapuche, se escuchan versiones de los chilenos sobre los mapuche.

Al respecto, Becerra (2011: 163-168) indica que los prejuicios y las prácticas discriminatorias hacia las personas que no forman parte de la cultura hegemónica de un país continúan presentes en el mundo. Agrega que en el caso de los indígenas esta cuestión es histórica, reflejando la ausencia de la aceptación de la diversidad y de valores inclusivos en la sociedad. Una de sus investigaciones en contexto escolar indígena, muestra la presencia de prejuicio étnico docente hacia estudiantes mapuche, lo que según indica la autora, devela la presencia de un sistema de creencias estereotipado; cuestiones que, según Becerra (2011: 164): "derivan en la generación de una dinámica relacional discriminatoria, que, en distintas formas, les transmite implícitamente mensajes de inferioridad y desvalorización".

Consecuentemente, personas con apariencia y nombre mapuche sienten vergüenza de 'sí mismas', sienten vergüenza de ser llamadas 'indias' y acuden al Registro Civil buscando cambiar su apellido, con la ilusión de que al hacerlo serán mejor tratados y tendrán más oportunidades de alcanzar una 'vida digna'. Además, como mostramos anteriormente, al dejar de hablar su lengua y hablar 
una otra lengua, la lengua que le es impuesta, el sujeto inconscientemente pierde parte de su memoria discursiva y concomitantemente, al hablar otra lengua (la nacional) incorpora otras memorias y moviliza otros sentidos, que determinan otras interpretaciones del mundo y de sí mismo. Nos preguntamos: ¿quiénes son esos mapuche ahora?, ¿qué quieren para el futuro? En el país, es de conocimiento general que especialmente en la VIII Región, la IX Región, la X Región y el Área Metropolitana hay espacios donde se concentra la población del Pueblo Mapuche y que en esos espacios hay comunidades mapuche que vivencian procesos de identificación fuertes y participan en diversas manifestaciones en defensa de la cultura, el territorio y la educación, entre otras; siendo la defensa de la lengua una de las demandas más sentidas. Podemos decir que incluso en esos lugares, donde el Pueblo Mapuche se identifica como colectivo y trabaja por la recuperación de sus derechos, la lengua se encuentra en condiciones de fragilidad y peligro de extinción y las comunidades y agrupaciones mapuche están preocupadas por lo que eso implica.

Concordamos con Payer (2001: 236) cuando plantea que "la lengua, en su modo específico de inscripción histórica y de existencia material, consiste, por la memoria discursiva en ella inscrita, de un material inseparable del sujeto que ella constituye" y también cuando agrega que, "la censura de la lengua constituye un modo particular de interdicción de la memoria, una vez que la lengua trae la memoria inscrita", por tanto, "interdictar la lengua implica, en ese sentido, interdictar un determinado modo de ser sujeto (por la lengua)" (Payer, 2001: 253). Eso significa que suprimir la diversidad lingüística imponiendo la lengua dominante también trae como consecuencia negar-nos la posibilidad de conocer al diferente en su otredad. Si aceptamos ese silogismo, nos queda claro que el desmantelamiento de 'las lenguas indígenas' y las memorias que éstas conllevan nos afecta a todos, es una merma significativa para el acervo lingüístico y cultural de la humanidad, es una pérdida insustituible para todos los que poblamos y poblarán este planeta.

\section{LA LENGUA COMO 'CUESTION DE PODER'}

En el mundo occidental se ha impuesto la versión de la historia de los conquistadores y a partir de esa mirada se ha construido la historia oficial de los distintos países. En América, primero la versión histórica de los conquistadores y luego la de los colonizadores. Y a través de esa mirada, se ha establecido la 
lógica de las hegemonías como el único estilo de relacionamiento posible entre pueblos diferentes. América fue colonizada por naciones europeas que impusieron su visión de mundo, sus costumbres y tradiciones. Lógica de relacionamiento que permanece hasta los días de hoy y no solamente en los países latinoamericanos. Como ya señalamos, el resultado de ese proceso ha sido el establecimiento de las lenguas de los conquistadores en desmedro de otras lenguas también presentes, que fueron excluidas, prohibidas, censuradas, olvidadas.

Con el nacimiento de las repúblicas en América, el discurso del estadonación se torna hegemónico. En Chile, una de las premisas de ese discurso es la unidad nacional. Chile es una República y todos sus ciudadanos son chilenos. Proceso histórico en el cual las memorias y lenguas indígenas son sacrificadas en pro de la unidad y también buscando 'favorecer', con el acceso al 'mundo civilizado' y al progreso occidental, a quienes se han considerado -y muchos aun consideran- grupos primitivos e ignorantes. Un proceso histórico que en mis investigaciones académicas denomino 'proceso de inter-in-comprensión' entre el sujeto discursivo chileno y el mapuche -como mencioné anteriormente-, donde no existe diálogo o interlocución, donde las comprensiones de la realidad son distintas: diferentes visiones de mundo, versiones distintas de la historia y hasta contradictorias u opuestas, entre otras cosas. Diferencias que en Chile han sido instaladas como "conflicto".

De acuerdo a la visión conquistadora-colonizadora de sometimiento del otro, del diferente, que orientó a los europeos que llegaron a estas tierras y a sus descendientes, el estado ha construido un discurso en pro de la unidad nacional, ocultando, negando, borrando las diferencias. Apoyándose en el concepto de igualdad -que ya significamos-, que en el discurso hegemónico estabilizado en la sociedad de los chilenos tendría el efecto de sentido de que todos tienen los mismos derechos, deberes, beneficios y oportunidades. Cuestión que -en relación a las lenguas- Pfeiffer (2001a: 182) describe como la búsqueda de una unidad lingüística, que ha sido y es parte constitutiva de todo proceso de organización social en torno a una unidad identitaria, en el proceso socio-histórico de la sociedad occidental. Siendo, a su vez, parte constitutiva de todo proceso de legitimación de una lengua, el apagamiento de otras lenguas que están en funcionamiento en una dada sociedad.

En esa lógica, el estado chileno ha buscado la transformación del mapuche desde su forma-sujeto histórico a la forma-sujeto jurídico, haciéndolo despojarse de 
todo lo que le es propio para transformarse en un chileno más, donde el abandono del mapuzugun y la adquisición del castellano ha sido un objetivo del estado, materializado en las primeras leyes de educación de la República, como política de escolarización. En esa perspectiva -y haciendo una síntesis de lo expuesto en este artículo- es posible señalar que a través de la imposición del castellano lo que se impone es una memoria y una cultura, la nacional, a lo que se suma la imposición de la versión de la historia del colonizador. Como resultado, hoy tenemos el olvido, el retroceso de las lenguas indígenas, lo que se traduce en que el indígena paulatinamente va perdiendo la identificación con su lengua y como sujeto indígena. Sin embargo, como indicamos en nuestra tesis de postdoctorado (Soto, 2006: 79), el proceso de silenciamiento en la constitución de las relaciones de poder entre los mapuche, la sociedad chilena y el estado nacional también ha significado y significa a través de procesos de resistencia de los mapuche, reforzando sus procesos históricos de identificación.

Procesos históricos (contrapuestos) que interpelan a la sociedad chilena que discrimina negativamente al indígena, a través de un estilo de discurso (formulado en la lengua nacional) que lo descalifica, que niega al 'otro', al 'diferente', al 'colonizado'. Un tipo de discurso asociado a la sociedad nacional hegemónica, que al mismo tiempo silencia a las poblaciones indígenas, las omite, les niega la palabra; mientras habla por esas poblaciones y busca soluciones a sus problemas.

Así, la forma en que el indígena se significa en la actualidad nos muestra que la interdicción de su lengua ha significado no tan solo el olvido del mapuzugun sino que también de la memoria inscrita en la lengua, lo que redunda en decir que paulatinamente este sujeto 'transita' hacia los sentidos estabilizados por el discurso del sujeto winka, que es quien tiene derecho a la palabra y quien habla (en la lengua nacional) desde la posición-sujeto winka o chileno. Consecuentemente, en ese proceso histórico caracterizado por un estilo de 'contacto' marcado por el discurso de la igualdad (que en su polisemia, al tiempo que considera al mapuche un chileno más, enmascara la desigualdad que, entre otras cosas, lo considera inferior), paulatinamente se produce el olvido de lo que 'pertenecía' a los distintos grupos indígenas y los identificaba, proceso que poco a poco resulta en la homogeneización cultural, 'awinkamiento' o 'chilenización' del sujeto indígena. Hay pérdida de las memorias, las lenguas y las 'culturas indígenas'. Se produce la identificación del indígena con el chileno y como resultado, poco a poco el indígena acepta (la imposición de) la educación y el progreso occidental. 
Sin embargo, la chilenización de los indígenas no ha sido fácil para el estado y la resistencia indígena marca los procesos socio-históricos del país hasta los días de hoy (Soto, 2010: 242; Soto, 2011a: 167). Sabemos que las movilizaciones indígenas han dado cada vez más visibilidad al sujeto indígena en Chile y con certeza en los últimos tiempos han sido un elemento importante que ha dado origen a una legislación orientada al mundo indígena, como es el caso de la Ley Indígena no 19.253, del 05 de octubre de 1993 (Soto, 2010: 243). En esta reflexión no vamos a discutir los motivos específicos de esta ley, ya que no es el objetivo de este artículo. Nos interesa apuntar que a pesar de sus faltas e inespecificidades, la Ley no 19.253 , entre otras cosas, aporta reconociendo la necesidad de la "conservación de los idiomas indígenas", su "difusión" (Gobierno de Chile, 2007: 25) y coloca en discusión, con el peso de la ley, la posibilidad de poner en práctica en Chile la Educación Intercultural Bilingüe (Gobierno de Chile, 2007: 27), además de otorgar un espacio institucional a estos asuntos, a través de la creación de la Corporación Nacional de Desarrollo Indígena (CONADI). Por tanto, consideramos que a partir de esta ley hay un cambio incipiente en la política lingüística y de escolarización en Chile.

También es importante destacar la ratificación del Convenio 169 en Chile, el 15 de septiembre de 2008, que a partir de su promulgación se transforma en una ley de la república. A pesar de que el 04 de septiembre de 2009, días antes de que entrara en vigencia, se dictó el Decreto 124 que reglamenta y limita su utilización (Gobierno de Chile, 2009a). Aún es temprano para evaluar lo que este convenio puede significar para los indígenas presentes en Chile, para las relaciones interculturales y las políticas públicas. Sin embargo, por el momento podemos destacar como uno de sus aportes significativos, el reconocimiento de la existencia de pueblos indígenas en Chile (Gobierno de Chile, 2009b: 15) y no sólo de individuos indígenas, como es el caso de la Ley no 19.253 (Gobierno de Chile, 2007: 12-13). Pues eso implica -como se puede leer en el texto del convenio- reconocer la cultura y la lengua, reconocer la necesidad de instaurar una educación adecuada a los distintos pueblos y/o naciones indígenas presentes en el país, entre otras cosas. Y con relación a la lengua, el Convenio 169 señala de manera específica que: "deberán adoptarse disposiciones para preservar las lenguas indígenas de los pueblos interesados y promover el desarrollo y la práctica de las mismas" (Gobierno de Chile, 2009b: 21). O sea, en teoría, la validación de ese tratado internacional como ley de la República daría comprensiones que 
permitirían restituir derechos de los 'pueblos indígenas' en Chile y cambiar la forma en que se establecen las relaciones llamadas 'inter-étnicas' en el país. En síntesis, el convenio coloca en circulación un discurso que permitiría pensar la diferencia como elemento constitutivo del estado-nación Chile.

A manera de corolario, de acuerdo a lo que discutimos a lo largo de este artículo, reiteramos que la memoria discursiva de un pueblo es decisiva si pensamos en su permanencia y sus proyecciones hacia el futuro. Por otro lado, queda claro que la lengua constituye al sujeto y que el lenguaje es una herramienta insustituible si queremos comprender como un pueblo se identifica y cómo interpreta la realidad. Así siendo, todo esfuerzo para la recuperación y mantenimiento de las lenguas indígenas es fundamental. Sin olvidar que pensar en las lenguas indígenas es también pensar en la lengua nacional, en otras palabras, es pensar las lenguas en relación; lenguas que, como expone Orlandi (1998b: 7), no son homogéneas y se constituyen en regiones cuya estabilidad es desigual, donde los límites entre ellas son frágiles, llenos de matices, lo que da origen a todo tipo de 'mezclas' lingüísticas. Sin olvidar además, como menciona la misma autora, que toda lengua nacional se ha constituido y se constituye entre enfrentamientos, alianzas, oposiciones, ambigüedades y tensiones con otras lenguas (Orlandi, 1998b: 9).

\section{CONSIDERACIONES FINALES}

Cuando en América Latina se discute sobre otredad, resulta fundamental reflexionar sobre las 'lenguas indígenas'. Con ese apelo, en este artículo discutimos la lengua mapuche y su movimiento, con el objetivo de comprenderla en su proceso histórico; pensando la relación Lengua/Nación/Estado y los sujetos sociohistóricos que esa relación constituye. En otras palabras, abordamos el mapuzugun colocando cuestiones que vinculan el estudio del lenguaje con movimientos de la historia y del sentido, en la constitución de la sociedad chilena, buscando comprender las relaciones que se han dado y se dan entre el estado y el pueblo mapuche, inserto en el espacio jurídico de los chilenos.

Mostramos que la lengua es fundamental en los procesos de constitución e identificación del sujeto y afirmamos que los procesos de negación y prohibición de una lengua atentan contra el sujeto discursivo. Desde ese lugar de sentidos, podemos asegurar que la lengua es un derecho inalienable, o sea, algo que no se debe enajenar, un derecho indiscutible. Pensamos en función de las palabras que tenemos a disposición. Por tanto, para el 'sujeto indígena' su lengua es constitutiva 
de $s u$ lugar como 'sujeto indígena' y es con ella que define $s u$ filosofía, su mirada hacia el mundo.

En esa perspectiva, considero productivo terminar esta reflexión sobre el mapuzugun y los procesos de colonización que han atravesado y atraviesan su trayectoria, dilucidando respecto a algunos de los desafíos que el pueblo mapuche, el estado nacional y la sociedad chilena tienen en relación al futuro de esta lengua.

En primer lugar, es necesario visibilizar al sujeto indígena como un otro. Eso significa, entre otras cosas, vehicular (colocar en circulación) el discurso del 'sujeto indígena', para que la 'escucha' ${ }^{10}$ del discurso de ese sujeto otro sea posible, lo que posibilitaría el re-conocimiento de ese sujeto otro y, concomitantemente, posibilitaría de-significar el discurso hegemónico, vaciándolo de los prejuicios $\mathrm{y}$ estereotipos (que de-significan al sujeto indígena). Al respecto (y en el mismo sentido), también es necesario visibilizar la forma en que funcionan las categorizaciones como: colonizador/colonizado, superior/inferior, donador/ beneficiario, sabio/ignorante, capaz/incapaz y otras parecidas, de manera que la de-significación de los sentidos pre-construidos que ellas 'arrastran' pueda dar lugar a nuevas comprensiones de las relaciones sociales en este país. Asimismo, la visibilización del discurso de los mapuche (que por el momento es incipiente) en los espacios sociales, educativos e institucionales, podría conducirnos, efectivamente, al re-conocimiento de Chile como un país multicultural, donde la multiculturalidad podría ser significada como una de nuestras grandes riquezas.

A partir de ese re-conocimiento, es necesario buscar espacios de interlocución entre los pueblos y/o naciones 'indígenas', el estado y la sociedad chilena, para que efectivamente las 'lenguas indígenas' puedan 'ser dichas'. Al respecto, la participación de los 'indígenas' en el desarrollo de metodologías de enseñanza de estas lenguas es fundamental, lo que para el momento actual también califico como un proceso incipiente.

Finalmente, debo registrar que considero este momento de la humanidad como el umbral entre lo antiguo y lo que puede 'llegar a ser', tanto en el ámbito académico como en los espacios socio-políticos. Estamos en un momento particular, donde se comienzan a pensar nuevas realidades o las realidades pueden ser pensadas de nuevas maneras, lo que -a diferencia de tiempos pretéritosposibilitaría que las lenguas sean administradas por quienes las hablan y por tanto las conocen, estableciendo nuevas institucionalizaciones. No sabemos qué va

${ }_{10}$ Término técnico del Análisis de Discurso y del Psicoanálisis. Tiene el sentido de 'escuchar discursivamente' (Soto en Orlandi, 2012: 40). 
a ocurrir. No obstante, se comienzan a visibilizar discursos, percepciones de la realidad, voces, que durante siglos fueron silenciadas. Los 'indígenas' hasta ahora omitidos, negados, reprimidos, o bien, 'convidados' a integrarse y ser un chileno más, en este momento tienen la posibilidad -el 'derecho' y el 'deber', si es posible decirlo de esa manera- de participar en la construcción de lo que les pertenece, como es el destino de sus lenguas.

Es tiempo de que los pueblos y naciones 'indígenas' 'tomen la palabra' y definan los mecanismos y estrategias para re-colocar sus lenguas en circulación. Es de vital importancia que no se omitan, que participen activa y efectivamente en el rescate de sus lenguas y aseguren su permanencia. De esa forma, no sólo se tiene la posibilidad de recuperar, fortalecer y asegurar el destino de las 'culturas indígenas', sino también de implementar estilos de relacionamiento no más de dominación y sometimiento, sino de complementariedad y co-existencia -entre las personas y los diversos grupos y pueblos que constituyen este país como parte de un planeta diverso-, donde sea posible vivenciar formas de convivencia armoniosa, reconociendo al otro, al diferente.

Concordamos con Orlandi (1988b: 8-9), cuando asegura que la cuestión del lenguaje es (y ha sido) siempre una cuestión de reconocimiento o de exclusión, del derecho (universal, particular, singular), de la identidad, la libertad o la coerción, por lo simbólico; donde la inyunción política a la "transformación" de los otros ha sido y continúa siendo fuerte cuando se trata del confronte entre europeos e indígenas, en que, a priori, el europeo o descendiente de europeo es considerado como estando en el auge del desarrollo, mientras los indígenas deben ser transformados para así alcanzar una mejor condición, habiendo ahí una relación de embate político-lingüístico ejemplar. En esa perspectiva, considerar cuestiones como las hegemonías, la unidad y la diferencia es inevitable, si lo que queremos discutir es la trayectoria y el futuro de las lenguas indígenas en América.

\section{REFERENCIAS}

Becerra, Sandra. "Valores de equidad y aceptación en la convivencia de escuelas en contexto indígena: la situación del prejuicio étnico docente hacia estudiantes mapuche en Chile", Revista de Educación, número extraordinario (2011): $163-181$.

Gobierno de Chile. Ley Indígena no 19.253. Temuco: Corporación Nacional de Desarrollo Indígena / CONADI, 2007. 
Gobierno de Chile. Ministerio de Planificación. Subsecretaría de Planificación. Texto. Decreto 124. Disponible en: <http: www.leychile.cl/ Navegar?idNorma=10066486. Publicado el 25 de septiembre de 2009>. [Consultado el 15 de diciembre de 2013, 2009a].

Gobierno de Chile. Convenio 169 de la Organización Internacional del Trabajo - OIT. Temuco: Ministerio de Planificación. Corporación Nacional de Desarrollo Indígena / CONADI, $2009 \mathrm{~b}$.

Foucault, Michel. A ordem do discurso. São Paulo: Edições Loyola, 1996.

Henry, Paul. "A história não existe?". En Eni Orlandi (Org.). Gestos de leitura: da história no discurso. Campinas/SP: Editora da UNICAMP, (1997): 29-52.

Lagazzi, Suzy. "Percursos que se cruzam. Leituras que se abrem". En Eni Orlandi (Org.), Para uma Enciclopédia da Cidade. Campinas-SP: Pontes; Labeurb/ Unicamp, (2003): 85-93.

Lagazzi, Suzy. Apresentação, em Pitombo-Oliveira, T. Fronteira discursiva. O paralelo $13^{\circ}$ e os sentidos da exclusão. Cáceres - MT: Editora Unemat, (2007): 11-12.

Maingueneau, Dominique. Termos-chave da Análise do Discurso. Belo Horizonte: Editora UFMG, 1998.

Maldidier, Denise. A inquietação do Discurso. (Re)ler Michel Pêcheux hoje. Campinas-SP, Brasil: Pontes, 2003.

Orlandi, Eni. A incompletude do sujeito - e quando o outro somos nós?, Série Cadernos PUC. Sujeito e Texto. São Paulo: EDUC (1988a): 9-16.

Orlandi, Eni. "Confronto pela linguagem". En Eni Orlandi (Org.). Política Lingüistica na América Latina. Campinas-SP: Pontes, (1988b): 7-9.

Orlandi, Eni. "Silêncio e implícito: produzindo a monofonia". En Eduardo Guimarães (Org.), História e sentido na linguagem. Campinas - SP: Pontes, (1989): 39-46. 
Orlandi, Eni. Terra à vista. Discurso do confronto: velho e novo mundo. São Paulo: Cortez. Campinas-SP: Editora da Universidade Estadual de Campinas, 1990.

Orlandi, Eni. As formas do silêncio. No movimento dos sentidos. Campinas - SP: Editora da Universidade Estadual de Campinas, 1995.

Orlandi, Eni. Interpretação. Autoria, leitura e efeitos do trabalho simbólico. Petrópolis - RJ: Vozes, 1996.

Orlandi, Eni. O próprio da Análise de Discurso. Escritos $n^{\circ}$ 3. Discurso e Política. Campinas - SP: LABEURB / Laboratório de Estudos Urbanos; Nudecri, (1998a): 17-22.

Orlandi, Eni. Ética e política Lingüística. Línguas e instrumentos lingüisticos $n^{\circ} 1$. Campinas - SP: Pontes Editores e Projeto História das Idéias Lingüísticas no Brasil, janeiro-junho, (1998b): 7-16.

Orlandi, Eni. Do sujeito na história e no simbólico. Escritos $n^{\circ} 4$. Contextos Epistemológicos da Análise de Discurso. Campinas - SP: LABEURB / Laboratório de Estudos Urbanos; Nudecri, (1999): 17-26.

Orlandi, Eni. Reflexôes sobre escrita, educação indígena e sociedade. Escritos $n^{\circ}$ 5. Escrita, escritura, cidade. Campinas - SP: LABEURB / Laboratório de Estudos Urbanos; Nudecri, (1999a): 7-22.

Orlandi, Eni. "Maio de 1968: os silêncios na memória”. En Achard, Pierre et al. Papel da memória. Campinas - SP: Pontes, (1999b): 59-71.

Orlandi, Eni. "O objeto de ciência também merece que se lute por ele”. En Denise Maldidier. A inquietação do Discurso. (Re)ler Michel Pêcheux hoje. Campinas - SP, Brasil: Pontes, (2003): 9-13.

Orlandi, Eni. Análisis de Discurso: principios y procedimientos. Santiago de Chile: Editorial LOM / Universidad Metropolitana de Ciencias de la Educación, 2012.

Payer, Onice. "Memória da língua: imigração e nacionalidade”. - Tese de doutorado em Lingüística. Universidade Estadual de Campinas / UNICAMP - IEL. Campinas - SP, 1999. 
Payer, Onice. "A interdição da língua dos imigrantes (italianos) no Brasil: condiçôes, modos, consequências". En Eni Orlandi (Org.), História das Idéias lingüisticas. Construção do saber metalingüistico e constituição da lingua nacional. Campinas - SP: Pontes; MT: Unemat Editora, (2001): 235-255.

Pêcheux, Michel. Semântica e Discurso. Uma crítica à afirmação do óbvio. Campinas - SP: Editora da UNICAMP, 1995.

Pêcheux, Michel; Fuchs, Catherine. "A propósito da Análise Automática do Discurso: atualização e perspectivas". En Francoise Gadet y Tony Hak. Por uma Análise Automática do Discurso: uma introdução à obra de Michel Pêcheux. Campinas - SP: Editora da Unicamp, (1997): 163-252.

Pêcheux, Michel; Gadet, Francoise. Há uma via para a Lingüística fora do logicismo e do sociologismo? Escritos $n^{\circ} 3$. Discurso e Política. Campinas SP: LABEURB / Laboratório de Estudos Urbanos; Nudecri, (1998): 5-16.

Pfeiffer, Claudia. Bem dizer e retórica: um lugar para o sujeito. Relatos. Publicação do Projeto: História das Idéias Lingüísticas no Brasil, ética e política das línguas: ética e política das línguas. Campinas SP: UNICAMP - USP, junho (2001): 13-23.

Pfeiffer, Claudia. A língua nacional no espaço das polemicas do século XIX/XX". En Eni Orlandi (Org.) História das Idéias lingüisticas. Construção do saber metalingüistico e constituição da língua nacional. Campinas - SP: Pontes; MT: Unemat Editora, (2001a): 167-183.

Rodríguez Alcalá, Carolina. O sentido público no espaço urbano: a questão da língua. Relatos. Publicação do Projeto: História das Idéias Lingüísticas no Brasil: ética e política das línguas. Campinas - SP, Brasil. UNICAMP USP, 7, junho (2001): 25-36.

Soto, Elba. "Mapudungun e os processos de escolarização dos mapuche no discurso governamental e pedagógico no Chile. Campinas-SP, Brasil. UNICAMP. Tese (pós-doutorado) - Universidade Estadual de Campinas / UNICAMP - IEL. Campinas - SP, Brasil, 2006. 
Soto, Elba. Sonhos e lutas dos mapuche do Chile. Campinas - SP, Brasil: Centro de Memória UNICAMP/CMU \& Editora Arte Escrita, 2007.

Soto, Elba. "Las voces de la tierra: el discurso mapuche por la autodeterminación indígena en América", Revista ALASRU Nueva Época, n. 5. América Latina: Realineamientos politicos y proyectos en disputa (2010): 235-254.

Soto, Elba. "Violencia en Territorio mapuche: discursos en pugna", Revista Electrónica Educación y Humanidades 1/2 (2011a):166-194.

Soto, Elba. "Los mapuche de Chile significados a partir de su discurso", Campinas - SP, Brasil. RURIS, Revista do Centro de Estudos Rurais. UNICAMP-IFCH 3/2, 2009-2010 (2011b): 99-124.

Soto, Elba. Prólogo. En Eni Orlandi. Análisis de Discurso:principios y procedimientos. Santiago: Editorial LOM - Universidad Metropolitana de Ciencias de la Educación, (2012): 11-15. 